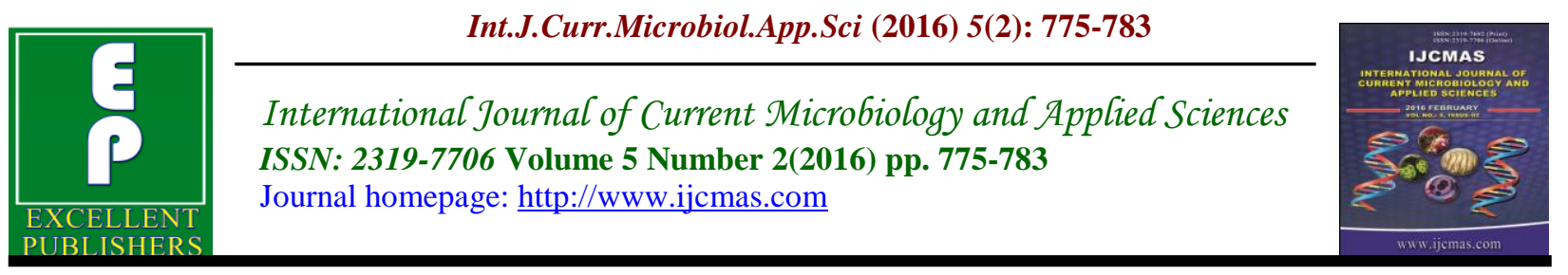

Original Research Article

doi: http://dx.doi.org/10.20546/ijcmas.2016.502.088

\title{
A Study on the categorization and Mycological profile of chronic fungal Rhinosinusitis in a Tertiary care hospital
}

\author{
K.Kavitha*, N.Rathnapriya, K.G.Venkatesh and G.Jayalakshmi \\ Department of Microbiology, Govt. Thiruvannamalai Medical College, \\ Vengikkal, Thiruvannamalai-606604, India \\ *Corresponding author
}

\begin{abstract}
A B S T R A C T
Keywords

Fungal sinusitis, Categories, antifungal Susceptibility testing, microbroth dilution.

Article Info

Accepted:

28 January 2016

Available Online:

10, February 2016

This study was conducted in a tertiary care hospital to evaluate the occurrence of Chronic fungal rhinosinusitis in patients admitted in a tertiary care hospital.AIM: To isolate the fungi causing chronic fungal rhinosinusitis, to categorise them, to study the susceptibility pattern of the isolates to anti fungal drugs. Processing and identification of isolates were done following standard operating procedures. CFRS was noted in $11 \%$ of the cases in the present study. Allergic fungal sinusitis was the most common (67\%). Aspergillus flavus was most commonly isolated (46.5\%). A.flavus was the most common isolate in all categories except CIFRS. All isolates were sensitive to Amphotericin B and Itraconazole Categorisation of CFRS is essential and helps to decide the best treatment option for the patient. Anti fungal sensitivity testing should be done as a routine for all cases.
\end{abstract}

\section{Introduction}

Rhinosinusitis is a common disorder affecting approximately $20 \%$ of the population at some time of their lives. Fungal sinusitis is being increasingly recognized in persons of all age groups, resulting in great socioeconomic effects. Previously, 5-15\% of cases of chronic rhino sinusitis cases were thought to be of fungal etiology. The patients have high morbidity and even may have high mortality especially those having acute invasive fungal rhinosinusitis (Rajiv C Michael, 2008).
Despite recognition of fungal rhinosinusitis (FRS) as a serious disease entity for more than two centuries, The disease is often neglected and misdiagnosed especially in developing countries like India, where FRS is one among the neglected diseases. Few studies have been done to quantitate the impact of fungi in the pathogenesis of sinusitis in India and fewer in Tamilnadu. This study was conducted in a tertiary care hospital to evaluate the occurrence of fungi as etiology for the occurrence of 
rhinosinusitis in patients admitted with a radiological diagnosis of rhinosinusitis and undergoing diagnostic and therapeutic endoscopic procedures for the same.Resistance to antifungals is an emerging concern as resistance of Aspergillus spp to standard antifungals have been noted and reported.

Hence, anti fungal susceptibility testing is advised for isolates causing fungal rhinosinusitis, particularly for invasive forms, chronic granulomatous forms and those occurring in immunocompromised.An attempt has been made in this study to try and compare different methods of susceptibility testing for filamentous fungi.

The main aim of this study includes to isolate, identify, speculate and study the susceptibility pattern of the fungi causing chronic fungal rhinosinusitis. And also to categorise the types of fungal sinusitis and to assess the risk factors favouring fungal involvement of paranasal sinuses.

\section{Materials and Methods}

This study was conducted in the Institute of Microbiology, Madras Medical College in association with Upgraded Institute of Otorhinolaryngology, Rajiv Gandhi Government General Hospital, Chennai. All consecutive Patients $>18$ years of age within the study period (2 years) with Radiologically proven sinusitis with Symptoms > 12 weeks duration whose functional endoscopic sinus surgery and/or diagnostic nasal endoscopy sampling or clinical condition is suggestive of fungal involvement in the pathogenesis of the disease were included in the study.

Approval was obtained from the Institutional Ethical Committee. Informed consent was obtained from the study population. Patients were interviewed by structured questionnaire. Statistical analysis were carried out using Statistical Package for Social Sciences (SPSS) and Epi-Info softwares.The proportional data of this cross sectional study were tested using Pearson's Chi Square analysis test and Fisher exact probability test.

\section{Case Definitions}

\section{Invasive Fungal Sinusitis (CIFS)}

Diagnostic criteria for invasive fungal infections as defined by deShazo (1997):

Mucosal thickening or air fluid level compatible with sinusitis on radiography.

Histopathological evidence of hyphal forms within the sinus mucosa, submucosa, blood vessel or bone.

To diagnose Granulomatous Invasive Sinusitis (CGFRS), histopathological evidence of hyphal forms within the sinus mucosa, submucosa, bloodvessel or bone in association with granuloma containing giant cells.

\section{Fungal Ball (FB)}

Diagnostic criteria for fungal ball as defined by deShazo(1997)

Radiological studies showing sinus opacification often associated with floccular calcifications.

Mucopurulent cheesy clay like material presenting at a single sinus at time.

Histopathological evaluation showing dense agglomeration of hyphae separate from adjacent respiratory mucosa and absence of allergic mucin. No fungal invasion of tissue or mucosa. 


\section{Allergic Fungal Rhinosinusitis (AFRS)}

Patients with a combination of the following findings were diagnosed as having

AFS as per diagnostic criteria described by Bent and Kuhn (1994):

Radiologically proven sinusitis.

Presence of allergic mucin within nasal cavity or sinuses. Demonstration of fungal hyphae in allergic mucin. Absence of fungal invasion in histopathology. Absence of diabetes, immunodeficiency or recent treatment with

\section{Recent treatment with Immunosuppressants}

Invasive fungal infections are defined in terms of "PROVEN", "POSSIBLE"; "PROBABLE" (Ascioglu et al., 2002).

PROVEN:POSITIVE culture obtained by a sterile procedure from a normally sterile site and clinically and radiologically abnormal site consistent with infection

PROBABLE: Atleast one criteria from host section, one microbiological criteria and one major or two minor clinical criteria from an abnormal site consistent with infection.

POSSIBLE: Atleast one criteria from host section and one microbiological or one major (or two minor) clinical criteria from an abnormal site consistent with infection.

\section{Criteria}

\section{Host Factors}

Neutropenia $\left(>500 / \mathrm{mm}^{3}\right.$ for $>10$ days) or coexistent AIDS, Persistent fever $>96$ hours refractory to antibiotics, Body temperature> $38^{\circ} \mathrm{C}$ or $<36^{\circ} \mathrm{C}$, Recent or current use of immunosuppressive agents or steroids $>3$ weeks

Microbiological criteria:Positive result of culture or findings of cytological /direct microscopic evaluation for mould from sinus aspirate sample

Major: Suggestive radiological evidence of invasive infection in sinuses(involvement of sinus walls, neighbouring structures and skull base)

Minor: Upper respiratory tract infections, Nose ulceration or eschar, Periorbital swelling, Maxillary tenderness, Perforation of hard palate

\section{Sample collection and processing}

Tissue biopsies or endoscopic aspirates were transported immediately in a sterile gauze moistened with sterile saline solution in a screw capped sterile container. Care was taken so that the specimen was not frozen or allowed to dehydrate before culture. When processing tissue for the recovery of fungi, the use of a mortar or tissue grinder was avoided (Elmer V Koneman). The tissue was minced into $1 \mathrm{~mm}$ cubes with a sterile scissors or a sharp scalpel blade and the tiny fragments were placed directly on the agar. Sabouraud Dextrose Agar was used for primary isolation (Elmer $\mathrm{V}$ Koneman). Direct examination was done by Potassium hydroxide $(\mathrm{KOH})$ mount preparation(Elmer $\mathrm{V}$ Koneman). All isolates were identified using standard methods. Anti fungal susceptibility testing was done by CLSI micro broth dilution method.

\section{Results and Discussion}

Of a total of 380 cases of Chronic Rhinosinusitis who underwent FESS and DNE during the study period, 80 cases which fulfilled the inclusion criteria were 
included in the study. Of the 80 cases, 43 cases were recognized as chronic fungal Rhinosinusitis (11.3\%).

Fungal Rhinosinusitis is a increasingly recognized entity among cases of chronic rhinosinusitis. The importance is increasing due to the morbidity and mortality caused by FRS.This study was conducted among 380 cases of Chronic Rhinosinusitis who underwent Functional endoscopic sinus surgery and Diagnostic nasal endoscopy at the Upgraded Institute of Otorhinolaryngology during the study period. 80 cases which fulfilled the inclusion criteria were included in the study. Of the 80 cases, 43 cases were recognized as chronic Fungal Rhinosinusitis. Overall incidence of FRS was $11.3 \%$ in our study.AFRS was the most common type identified(fig 1). Shiv sekar chatterjee et al.,(2009) have recorded an incidence of 5-15\%.

In the 43 chronic fungal rhinosinusitis cases, Hyperglycemia was noted as a risk factor in 8 cases $(18.6 \%)$ (Table 1).When comparing chronic invasive rhinosinusitis and other subtypes, Hyperglycemia was observed as a risk factor in $75 \%$ (6 of 8 cases) of Chronic Invasive Rhinosinusitis and the same risk factor was observed in only $6 \%$ of other subtypes $(p=0.002)$. This shows the increased tendency of fungal infections to occur in a more invasive form if there is underlying hyperglycemia due to uncontrolled diabetes. Varying data are available regarding the existence of hyperglycemia as a risk factor for development of the disease. Michael et al.,(2008) reported uncontrolled diabetes in $38.8 \%$ of cases of invasive fungal sinusitis and they have suggested that the study population may have undiagnosed Diabetes mellitus since Diabetes is known to be extremely common in India. Mohapatra et al.,( 2010), has observed that hyperglycemia was noted in $44.8 \%$ of cases. Diabetes causes increased chance of fungal infection because of impaired neutrophil function (Jones JMR,1994). Diabetes atlas 2006 by International Diabetes Federation has observed that the current number of people affected by Diabetes is 40.9 Million and is expected to rise to 69.9 Million by 2025 unless preventive measures are taken. So, increased vigilance will be needed to identify fungal rhinosinusitis in the future.

Asthma/Chronic Eczema was noted in $46 \%$ of other categories(which includes AFS,CGFRS and FB)(Table 1). 16 patients of the 29 patients (55\%) who had Allergic fungal sinusitis had given a history of Asthma and /or Chronic eczema. ( $\mathrm{p}<0.001)$ This was found to be statistically significant implying that asthma and other atopic illnesses were significantly associated with AFS. Asthma and associated atopic illnesses were noted in $49.1 \%$ of patients with AFS in a study done by Suraiye.H.AlDousary etal, (2008), 50\% by Manning et al (1998).

Majority of the fungi isolated were Aspergillus sp. in particular A.flavus(46.5\%)(Table 2).A.flavus was the commonest isolate in AFS(55\%),Fungal ball $(100 \%)$ and Chronic granulomatous disease.(50\%).In chronic invasive form, however,Rhizopus species were the most commmonly isolated(50\%).A.niger was the $2^{\text {nd }}$ most commonly isolated in AFRS.In India, A.flavus is isolated in $>80 \%$ of cases of AFRS $^{3,4,7,10,14}$ This is attributed to the normal fungi present in the soil and environment of tropical countries like India. Shiv sekar chatterjee et al describes A.flavus as the main etiological agent in CGFRS also $^{15}$.This parallels our study. In our study Rhizopus species predominated in the invasive form of the disease. On the contrary, Chakrabarti et al describes A.fumigatus as the commonest fungi causing CIFRS $^{5}$. 
Table.1 Comparison between Risk Factors Associated With Chronic Invasive Fungal Sinusitis and other Categories of CFRS

\begin{tabular}{l|r|}
\multicolumn{1}{c|}{ Categories } & \%n=43 \\
\hline 1. AFRS $(n=29)$ & $68 \%$ \\
\hline 2. FB $(n=2)$ & $5 \%$ \\
\hline 3. CGFRS $(n=4)$ & $9 \%$ \\
\hline 4. CIFRS $(n=8)$ & $19 \%$ \\
\hline
\end{tabular}

Table.2 Etiological Fungal Agents of Chronic Fungal Sinusitis and their Relative Frequency of Isolation

\begin{tabular}{|c|c|c|c|c|c|}
\hline SPECIES & $\begin{array}{c}\text { AFS } \\
(\mathrm{N}=29)\end{array}$ & $\begin{array}{c}\text { FUNGAL } \\
\text { BALL } \\
(\mathbf{N}=\mathbf{2})\end{array}$ & $\begin{array}{c}\text { CHRONIC } \\
\text { GRANULO } \\
\text { MATOUS } \\
(\mathrm{N}=4) \\
\end{array}$ & $\begin{array}{c}\text { CHRONIC } \\
\text { INVASIVE } \\
\quad(\mathbf{N}=8)\end{array}$ & $\begin{array}{c}\text { TOTAL } \\
(n=43)\end{array}$ \\
\hline A.flavus & $\begin{array}{c}16 \\
(55.1 \%)\end{array}$ & $\begin{array}{c}2 \\
(100 \%)\end{array}$ & $\begin{array}{c}2 \\
(50 \%)\end{array}$ & $\begin{array}{c}1 \\
(12.5 \%)\end{array}$ & $\begin{array}{c}21 \\
(48.8 \%) \\
\end{array}$ \\
\hline Rhizopus spp & $\begin{array}{c}1 \\
(3.4 \%) \\
\end{array}$ & - & $\begin{array}{c}1 \\
(25 \%)\end{array}$ & $\begin{array}{c}4 \\
(50 \%) \\
\end{array}$ & $\begin{array}{c}6 \\
(13.9 \%)\end{array}$ \\
\hline A.fumigatus & $\begin{array}{c}3 \\
(10.3 \%)\end{array}$ & - & $1(25 \%)$ & $\begin{array}{c}1 \\
(12.5 \%)\end{array}$ & $\begin{array}{c}5 \\
(11.6 \%)\end{array}$ \\
\hline A.niger & $\begin{array}{c}3 \\
(10.3 \%) \\
\end{array}$ & - & - & - & $\begin{array}{c}3 \\
(6.9 \%) \\
\end{array}$ \\
\hline A.nidulans & - & - & - & $\begin{array}{c}1 \\
(12.5 \%) \\
\end{array}$ & $\begin{array}{c}1 \\
(2.3 \%)\end{array}$ \\
\hline A.clavatus & $\begin{array}{c}1 \\
(3.4 \%) \\
\end{array}$ & - & - & - & $\begin{array}{c}1 \\
(2.3 \%)\end{array}$ \\
\hline Penicillium spp. & $\begin{array}{c}1 \\
(3.4 \%)\end{array}$ & - & - & - & $\begin{array}{c}1 \\
(2.3 \%) \\
\end{array}$ \\
\hline $\begin{array}{c}\text { Paecilomyces } \\
\text { variotii }\end{array}$ & $\begin{array}{c}1 \\
(3.4 \%)\end{array}$ & - & - & - & $\begin{array}{c}1 \\
(2.3 \%)\end{array}$ \\
\hline $\mathrm{KOH}+/ \mathrm{NG}$ & $\begin{array}{c}4 \\
(13.8 \%) \\
\end{array}$ & - & - & $\begin{array}{c}2 \\
(25 \%)\end{array}$ & $\begin{array}{c}6 \\
(13.9 \%) \\
\end{array}$ \\
\hline Mixed growth & $\begin{array}{c}1 \\
(3.4 \%)^{*}\end{array}$ & - & - & $\begin{array}{c}1 \\
(12.5 \%) \#\end{array}$ & $\begin{array}{c}2 \\
(4.6 \%)\end{array}$ \\
\hline
\end{tabular}

*A.fumigatus + Rhizopus oryzae \#A.niger+Rhizopus oryzae 
Table 3 Minimum Inhibitory Concentration of Itraconazole To different Molds by Broth Dilution Method

\begin{tabular}{|l|c|c|c|c|c|c|}
\hline \multicolumn{1}{|c|}{ SPECIES } & \multicolumn{3}{|c|}{ AMPHOTERICIN } & \multicolumn{3}{c|}{ ITRACONAZOLE } \\
\hline & $\begin{array}{c}\text { SENSITIVE } \\
(\mathbf{M I C}<\mathbf{\mu g} / \mathbf{m l}) *\end{array}$ & $\begin{array}{c}\text { RESISTANT } \\
(\mathbf{M I C} \\
>\mathbf{2 \mu g} / \mathbf{m l})\end{array}$ & $\begin{array}{c}\text { MEAN } \\
\text { MIC } \\
(\boldsymbol{\mu g} / \mathbf{m l})\end{array}$ & $\begin{array}{c}\text { SENSITIVE } \\
(\mathbf{M I C}<\mathbf{8} \boldsymbol{\mu g} / \mathbf{m l}) *\end{array}$ & $\begin{array}{c}\text { RESISTANT } \\
(\mathbf{M I C} \\
\mathbf{>} \boldsymbol{\mu g} / \mathbf{m l})\end{array}$ & $\begin{array}{c}\text { MEAN } \\
\text { MIC } \\
(\boldsymbol{\mu g} / \mathbf{m l})\end{array}$ \\
\hline A.flavus(21) & 21 & - & 0.5 & 21 & - & 0.125 \\
\hline Rhizopus spp(6) & 6 & - & 0.5 & 6 & - & 0.25 \\
\hline A.fumigatus (5) & 5 & - & 0.25 & 5 & - & 0.0313 \\
\hline A.niger(3) & 3 & - & 0.125 & 3 & - & 0.125 \\
\hline A.nidulans(1) & 1 & - & 1 & 1 & - & 0.5 \\
\hline A.clavatus(1) & 1 & - & 1 & 1 & - & 0.25 \\
\hline $\begin{array}{l}\text { Penicillium } \\
\text { spp(1). }\end{array}$ & 1 & - & 0.5 & 1 & - & 0.125 \\
\hline $\begin{array}{l}\text { Paecilomyces } \\
\text { variotii.(1) }\end{array}$ & 1 & - & 0.25 & 1 & - & 0.25 \\
\hline
\end{tabular}

*Interpretive criteria currently not standardized.Studies show that MICs above $8 \mu \mathrm{g} / \mathrm{ml}$ are associated with treatment failure and < $8 \mu \mathrm{g} / \mathrm{ml}$ with clinical cure for Itraconazole and MICs above $2 \mu \mathrm{g} / \mathrm{ml}$ are associated with treatment failure and $<2 \mu \mathrm{g} / \mathrm{ml}$ with clinical cure for Amphotericin B.

\section{Fig i CATEGORISATION OF THE CASES OF FUNGAL SINUSITIS}

100

50

0

$\begin{array}{lcc} & \text { AFRS } & \text { FUNGAL } \\ \text { NUMBER } & 29 & \text { BALL }^{2} \\ \% & 67.77 & 4.6\end{array}$

\begin{tabular}{|cc}
\multicolumn{1}{c|}{ CGFRS } & CIFRS \\
\hline 4 & 8 \\
9.3 & 18.6 \\
\hline
\end{tabular}


Figure.2 KOH Mount Showing Septate Hyphae

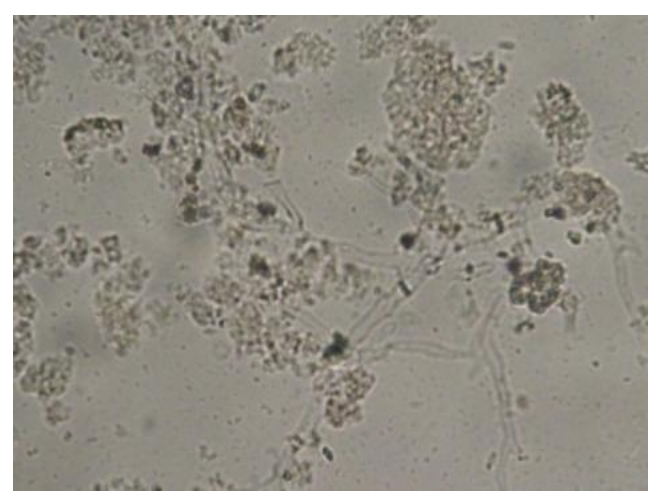

Figure.3 KOH Mount Showing Aseptate Hyphae

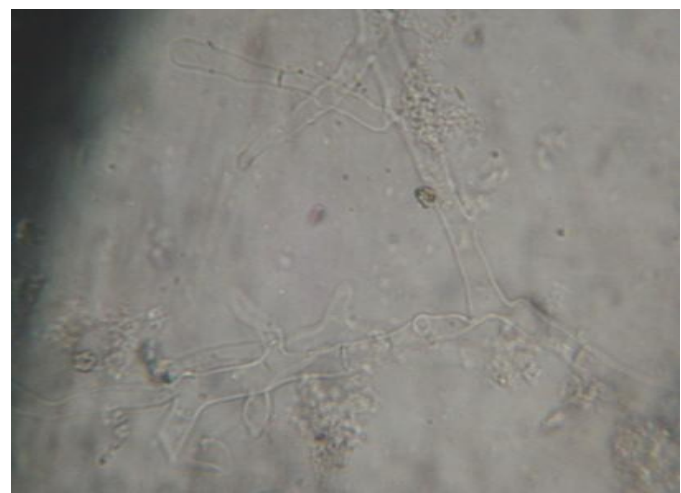

Figure.4 Microbroth Dilution for Antifungal Susceptibility Testing

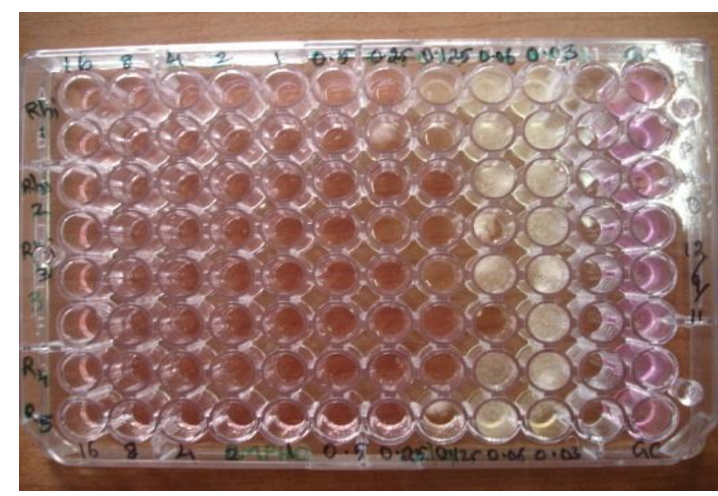

29 isolates of Aspergillus sp, 6 of Rhizopus $s p$ and 2 Penicillium $s p$. were taken up for antifungal susceptibility testing for Amphotericin B and Itraconazole. ATCC A.flavus 204304 was included in each panel as a reference strain.
All the fungal isolates were universally sensitive to both Amphotericin B and Itraconazole by broth microdilution method (Table.3). Geometric mean MIC ranged from $0.0313-1$ for both the antifungals. The MIC of reference strain was 0.5 and 0.25 for 
Amphotericin B and Itraconazole respectively which was well within the control limits prescribed by CLSI M38 A.

In conclusion, Chronic Fungal Rhinosinusitis largely impairs the active functioning of the patients in their day to day life and causes a significant morbidity and even mortality. This study was undertaken to assess the prevalence of CFRS, to isolate and identify the fungi \&their sensitivity pattern to standard antifungal agents and to study the risk factors favouring CFRS in patients undergoing functional endoscopic sinus surgery and diagnostic nasal endoscopy in a tertiary care hospital. CFRS was noted in $11 \%$ of the cases in the present study.

Categorisation of CFRS is essential and helps to decide the best treatment option for the patient. Patients with uncontrolled diabetes are at risk of acquiring invasive form of CFRS. Patients with documented asthma and associated atopic illnesses are at an increased risk of acquiring AFRS. Aspergillus flavus was most commonly isolated. Grave complications like orbital cellulitis, brain abscess, orbital granuloma, cavernous sinus thrombosis and cranial nerve palsies were seen in this study. Anti fungal sensitivity testing should be done as a routine for all cases when feasible as resistant strains are emerging. In life threatening invasive fungal infections, it is prudent to do microbroth/agar dilution for antifungal susceptibility testing.

\section{References}

1. Ascioglu S,J.H.Rex, de Pauw, et al.,2002.Invasive fungal infections cooperative group of the European organization for research and treatment of cancer;Mycoses study group of the National institute of Allergy and
Infectious diseases.Defining opportunistic invasive fungal infections in immunocompromised patients with cancer and haematopoietic stem cell transplants:an international consensus.Clin.Infect.Dis.34:7-14.

2. Bent JP, Kuhn FA. Diagnosis of allergic fungal sinusitis. Otolaryngol Head Neck Surg 1994;111: 580-88.

3. Chabra A, Handa KK, Chakrabarti A, et al. Allergic fungal sinusitis: Clinicopathological characteristics.Mycoses $\quad$ 1996;39:43741.

4. Chakrabarti A, Sharma SC, Chander J. Epidemiology and pathogenesis of paranasal sinus mycoses. Otolaryngol Head Neck Surg 1992;107:745-50

5. deShazo RD, O'Brien M,et al. A new classification and diagnostic criteria for invasive fungal sinusitis. Arch Otolaryngol Head Neck Surg 1997;123:1181-88.

6. deShazo RD, O'Brien M, et al. Criteria for the diagnosis of sinus mycetoma. $J$ Allergy Clin Immunol 1997;99:475-85.

7. Dhiwakar M, Thakar A, et al. Preoperative diagnosis of allergic fungal sinusitis.Laryngoscope 2003;113:688-94.

8. Elmer V Koneman, Gary W Procop, Paul C.Schreckenberger, Koneman's color atlas and textbook of diagnostic Microbiology, $6^{\text {th }}$ edition:Mycology,pg1160-

1163.Lippincott William and Wilkins ISBN 0-7817-3014-7.

9. Jones JMR, Moore-Gillon V. Destructive non-invasive paranasal sinus aspergillosis: Component of spectrum of disease. $J$ Otolaryngol 1994;23:92-96.

10. Manning SC, Holman M. Further evidence for allergic pathophysiology in allergic fungal sinusitis. Laryngoscope 1998;108:1485-96. 
11. Mohan.V.S Sandeep, R. Deepa, Epidemiology of type 2 diabetes Indian Scenario. Ind. J. Med. Research, 125, Mar 2007, pg : 217 - 230.

12. Mohapatra S,M Jain,I Xess,Spectrum of Zygomycoses in North India:An institutional experience.Indian Journal of Medical Microbiology,(2010)28(3):262-70.

13. Rajiv.C.Michael,Joy S Michael,Ruth H Ashbee, Mary Mathews.Mycological profile of fungal sinusitis:An audit of specimens over a 7 year period in a tertiary care hospital in Tamil nadu.2008.Indian Journal of Pathology and Microbiology51(4)493-6.
14. Rupa V, Jacob M, Mathews MS, et al. Clinicopathological and mycological spectrum of allergic fungal sinusitis in South India. Mycoses 2002;45:364-67.

15. Shiv Sekar Chatterjee,Arunaloke Chakrabarthy,et al.epidemiology and medical mycology of fungal sinusitis.Otorhinolaryngology clinics :A international journal,sep-dec 2009;1(1):1-13.

16. Suraiye H.Al Dousary,Allergic fungal sinusitis; radiological and microbiological features of 59 cases;Ann Saudi Med 2008,28(1):1721.

\section{How to cite this article:}

Kavitha, K., N.Rathnapriya, K.G.Venkatesh and Jayalakshmi, G. 2016. A Study on the categorization and Mycological profile of chronic fungal Rhinosinusitis in a Tertiary care hospital. Int.J.Curr.Microbiol.App.Sci.5(2): 775-783. doi: http://dx.doi.org/10.20546/ijcmas.2016.502.088 